NBER WORKING PAPER SERIES

\title{
EMPLOYED AND UNEMPLOYED JOB SEARCH: \\ A COMPARISON OF CHOICES \\ AND OUTCOMES AMONG YOUTH
}

Harry J. Holzer

Working Paper No. 1861

NATIONAL BUREAU OF ECONOMIC RESEARCH 1050 Massachusetts Avenue

Cambridge, MA 02138

March 1986

I would like to thank Dan Hamermesh and other seminar participants at Michigan State University for their comments. Eric Krupka provided excellent research assistance. Funding was provided by NSF Grant No. SES-8408876. The research reported here is part of the NBER's research program in Labor Studies. Any opinions expressed are those of the author and not those of the National Bureau of Economic Research. 
NBER Working Paper \#1861

March 1986

Employed and Unemployed Job Search:

A Comparison of Choices and Outoomes Among Youth

\begin{abstract}
Th1s paper presents evidence that young unemployed jobseekers choose higher levels of search effort (as measured by numbers of methods used and time spent per method) and lower relative reservation wages than do comparable employed seekers. The unemployed also have higher probabilities of gaining new employment, which reflect higher probabilities of recelving offers and espectally higher probabllities of accepting them; as well as slightly lower wages. These differences in outcomes between the two groups are at least partly explatined by differences in their respective search cholces. The evidence thus suggests that unemployed jobseekers have higher costs of search (from foregone earnings) than do the employed, causing the former to seek new Jobs more eager1y.
\end{abstract}

Harry J. Holzer Department of Economics Michigan State University East Lansing, MII 48824 
In recent years, job search models have been amended to allow for search by both employed and unemployed individuals. Among the issues addressed by empirical work on this topic has been the relative effectiveness of each type of search in producing employment outcomes. This issue is critical for determining whether or not job search is an important factor in explaining unemployment, since there may be little need to experience unemployment in searching for work. ${ }^{1}$

Unfortunately, the research to date on this issue has provided very conflicting evidence. Early papers by Mattila (1969) and Black (1980) argued that employed search produces higher wage offers than unemployed search. However, Kahn and Low (1982) argued that unemployed search produces higher wage offers, once the self-selection of individuals into each mode of search was accounted for. More recently, Gottschalk and Maloney (1985) presented evidence that employment status per se has no significant effect on whether Individuals thought they were "better off" in their new jobs, although involuntary job terminations prior to unemployment did result in more negative outcomes.

In this paper, I hope to clarify these issues by presenting new evidence on search choices and outcomes for employed and unemployed young men. In particular, the search choices analyzed will include the reported 
reservation wage, the number of search methods used, and the time spent per method by each searcher. The employment outcomes considered will be the probabilities of gaining new employment by receiving and accepting job offers, as we11 as the wages of offers received and accepted. The analysis is performed on data from the New Youth Cohort of the National Longitudinal Survey (NLS).

This paper thus builds on previous efforts by sorting through a more complete range of search outcomes, and by considering various search choices as sources of differences in outcomes between employed and unemployed searchers. A11 of this is done within the context of a search model that predicts differences in search choices and outcomes between the two types of Jobseekers, given differences in their costs of searching.

The first section of the paper summarizes the search model and its predictions regarding search cholces and outcomes. The second section reports the empirical results, while the third provides a summary and conclusion.

The main findings are that unemployed young jobseekers choose lower relative reservation wages and higher levels of search effort than do employed seekers. Both of these findings are consistent with the notion of lower utility while searching for the unemployed. Furthermore, those choices help to explain our additional findings of higher job gaining probabilities for the unemployed, which reflect higher probabilities of receiving offers and especially higher probabilities of accepting them; as well as their silghtly lower accepted wages. In short, the higher costs of search while being unemployed cause these individuals to exert more effort and to be less selective in pursuing new employment. 


\section{Theoretical Predictions Regarding Enployed and Unemployed Search}

A very standard result of the job search literature is that the probability of recelving a new job within a certain period is related to reservation wages and search effort in the following manner:

1)

$$
P_{E}=\pi(S E) \cdot\left(1-F\left(w^{r}\right)\right)
$$

where $P_{E}$ is the probability of gaining employment, ${ }^{r}$ is the reservation wage, $S E$ is search effort, $\pi$ is the probability of receiving an offer and $f\left(w_{0}\right)$ is the density function of wage offers facing an individual. Likewise, the expected wage of an individual conditional on gaining employment is related to his or her reservation wage:

2)

$$
E\left(w \mid w^{0}>w^{r}\right)=\frac{\int_{w}^{\infty} w f(w) d w}{\int_{w}^{\infty} f(w) d w}
$$

of course, the assumption that search effort affects offer probabilities but not wage offers is arbitrary and is made for the sake of simplicity.

Differences in these search outcomes between employed and unemployed searchers should therefore reflect differences in search choices SE and $w^{r}$; as well as possible differences in the offer and wage functions which the two groups face.

There are several reasons for expecting the search choices of the two groups to differ. It is well known that, ceteris parabus, reservation wages should be inversely related to search costs, which are defined as direct costs 
of search plus foregone earnings (Lippman and McCall, 1976). Thus the employed may have higher reservation wages due to lower costs of search, which in turn are made possible by the earnings which they continue to recelve while searching. Lower reservation wages for the unemployed may, in fact, be part of an explicit strategy in which search continues at a higher reservation wage after an unemployed worker accepts a low-wage job (Burdett, 1978).

Search effort is also likely to be lower for those having lower costs due to earnings. ${ }^{2}$ This factor, as well as the higher marginal value of leisure for those who also spend time working, should lead them to have lower levels of search effort than the unemployed as well. 3 of course, the cruclal assumption of lower search costs for the employed rests on the notion that nonwage income sources (such as Unemployment Insurance) and value of leisure time do not fully compensate the unemployed for their loss of earnings. The model also abstracts from the effects of temporary layoffs with high probability of recall on the search effort of the unemployed.

Given these assumptions, we would predict on the basis of Equations 1) and 2) that employed searchers have lower probabilities of receiving offers, lower probabilities of accepting offers, and higher wages when offers are accepted than do unemployed searchers. However, these predictions may change when some of the simple model's assumptions are relaxed. For instance, if search effort affects wage offers as well as offer probabilities (Kahn and Low, 1982), the higher wages of the employed will be reduced. Furthermore, the offer probability and wage offer functions might differ between the two groups if the technology of search varies across employment states. As an example, information and personal contacts may be more accessible to employed searchers. Differences in individual characteristics between the two may work in the same direction (if, for instance, the unemployed are a lower-skilled 
group on average). These factors might reduce or reverse the higher predicted probability of gaining employment for the unemployed, while raising the likelihood of higher recelved wages for the employed. Differences in the dynamics of search choices as the spell of search proceeds might also complicate the comparison. 4

Finally, all of the above is relevant only when initial employment status is exogenously determined. This is true for those whose jobs have been Involuntarlly terminated (Gottschalk and Maloney, 1985) as well as for those who are new entrants or reentrants to the labor force. In fact, the vast majority of the unemployed belong to one of these groups. 5 But for others, employment status whlle searching is endogenous--one may choose to either quit into unemployment before a new job is found or remain employed. Theoretical models of the quit decision for jobseekers have been developed by Barron and McCafferty (1977) and Burdett (1978) and have been empirically tested by Black (1981) and Kahn and Low (1982, 1984). For our purposes, we need only point out that the search choice differences predicted above should hold for job losers and labor force entrants, though not necessarily for the small number of unemployed who are job-leavers.

\section{Data and Empirical Results}

The data used in the empirical analysis below are part of the 1981 panel of the New Youth Cohort of the NLS. Despite 1 ts focus on youth, these data are very well-suited for this analysis because they contain very extensive information on search behavior and outcomes. In particular, individuals were asked whether or not they had searched for work in the previous month. If they had, they were then asked: which methods of search 
they had used, 6 the amount of time spent in the previous month on each method, ${ }^{7}$ whether or not a job offer resulted, the wage of any offer made, and whether or not the job was accepted. The number of search methods used and the amount of time spent on each are used here to measure search effort. The former can be thought of as a measure of extensive effort and the latter as intensive effort. ${ }^{8}$ An additional measure of search choice is provided by responses to a question about the lowest wage an Individual would accept on a hypothetical job offer, 1.e., the reservation wage. The data on job offers, acceptances, and wages are then used to measure the outcomes of search for each individual.

The sample used in the analysis includes nonenlisted and nonenrolled males between the ages of 16 and 23 who claimed to have searched for work in the previous month. ${ }^{9}$ Defining employment status of searchers was a bit more difficult. Since unemployed searchers who had accepted job offers might be Iisted as currently employed, current employment status could not be used alone to define status while searching. Instead, I define unemployed searchers to be those who are currently unemployed or those who had searched for and accepted jobs in the previous month and whose employment durations are thirty days or less. Unlike previous studies, the sample here includes labor force entrants and reentrants as well as job losers and leavers among the unemployed, as well as both successful and unsuccessful searchers. 10

Table 1 presents summary statistics on the search cholce vartables for employed and unemployed job seekers. All means are weighted to correct for the oversampling of low-income individuals in the NLS. The results show that the average unemployed jobseeker uses more search methods than does the employed seeker, and the difference between the two appears to be statistically significant. ${ }^{11}$ Intensive use of specific search methods, as 
TABLE 1

Search Cholces of

Employed and Unemployed Jobseekers

Means and Standard Deviations

Employed

Number of

Methods Used

Time Spent by

Those Using:

Friends/Relatives

Direct Contact

State Agency

News papers

0 ther Methods

Reservation Wages

Reservation Wages of Those with Offers
2.723

$(1.238)$

109.30

(478.37)

133.09

$(460.10)$

159.43

(220.12)

$$
\begin{gathered}
233.50 \\
(1834.78)
\end{gathered}
$$

33.25

$(34.09)$

$$
6.01
$$

(3.13)

$$
6.32
$$$$
\text { (3.01) }
$$

Unemployed

3.285

(1.261)

NOTE: Data are from the National Longitudinal Survey (NLS) New Youth Cohort, 1981 Panel. All means are weighted. Sample sizes are 438 for employed seekers and 609 for unemployed seekers. 
measured by time spent on each, is also substantially higher for the unemployed in all but one case. (The exception is the use of newspapers, where time spent is basically comparable between the two groups.) Finally, the reservation wages are significantly lower as we11, for all searchers and for those with offers. All of this confirms the predictions of the simple theoretical model outlined above, in which higher costs of search for the unemployed cause them to expend more effort while searching and to be more wllling to accept job offers when received.

Table 2 presents summary results on the outcome variables for employed and unemployed jobseekers. Again, all means are weighted to reflect population-wide estimates. The results show that a higher percentage of the unemployed have received offers in the previous month. Even more striking is the substantially higher percentage of those receiving offers who accept them among the unemployed. In particular, we find that employed searchers have rejected almost $60 \%$ of the offers which they have recelved in the past month, while unemployed searchers have rejected only about $20 \%$. Thus the 11kelihood of gaining a new job for an unemployed jobseeker is significantly higher than for an employed seeker on both counts. But as for wages, those offered are a bit higher for the employed, and those accepted are basically comparable between the two groups.

Taken together the results suggest a need to consider a broad range of search outcomes when discussing the effectiveness of search for each group, since data on wages imply falrly comparable outcomes between the two groups while data on offers and acceptances imply better outcomes for the unemployed. The results also suggest the importance of considering the cholces of search effort and reservation wages when comparing search outcomes for the employed and unemployed, since the summary results of Tables 1 and 2 


\title{
TABLE 2
}

\author{
Search Outcomes for \\ Employed and Unemployed Jobseekers \\ Means and Standard Deviations
}

\section{Employed}

\section{Percentage Gaining} New Employment

Percentage Receiving offers

Percentage Accepting Received offers

Wages of Recelved offers

Wages of Accepted offers
Unemployed

.123

.275

.294

.417 .809

4.79

$(1.76)$

4.68

$(2.50)$

4.83

$(1.90)$
4.87

$(2.67)$

NOTE: Example sizes for percentages gaining new employment and receiving offers are 438 for employed seekers and 609 for unemployed seekers. For percentage accepting received offers they are 127 and 192; for of fered wages they are 94 and 160; and for accepted wages they are 53 and 123 respectively. 
Imply that these cholces and outcomes may be linked. In particular, the higher search effort and lower reservation wages of the unemployed which we observe In Table 1 are theoretically consistent with their higher job-finding rates that we observe in Table 2 .

It is also noteworthy that wage offers are higher for the employed. Th1s suggests that wage offer distributions for the two groups of searchers may differ independently of search choices, a possibllity that was discussed above. But the separate data on wage offers and recelved wages also enable us to see whether or not the lower reservation wages of the unemployed are simply a product of their lower wage offers. A comparison of these data in Tables 1 and 2 implies that this is not the case, since the ratio of reservation wages to offered wages among those reporting both is substantially higher among the employed than among the unemployed -1.32 for the former and .99 for the latter, respectively. The data thus strengthen the argument that higher reservation wages among the employed reflect their lower search costs.

We can analyze these 1ssues more carefully by estimating equations for the various employment outcomes as functions of search cholces, employment status, and other variables. The equations are of the following form:

$$
P_{E}=P_{E}\left(X, N U S E, T_{j}, w^{r}, \text { UNEMP, } Q\right)+e_{1}
$$

4)

$$
P_{o}=P_{o}\left(X, N U S E, T_{j}, \text { UNEMP, } Q\right)+e_{2}
$$

$$
\mathrm{P}_{\mathrm{A}}=\mathrm{P}_{\mathrm{A}}\left(\mathrm{w}^{\mathrm{r}} / \mathrm{w}_{\mathrm{o}}, \mathrm{UNEMP}, \mathrm{Q}\right)+\mathrm{e}_{3}
$$

where ${ }_{E}, P_{0}$, AND $P_{A}$ are the probabilities of gaining employment, recelving $a$ 
job offer, and accepting an offer (conditional on recelving $1 t$ ) respectively; NUSE Is the number of search methods used and TIME $_{j}$ is the time spent on each of the five search methods $j$; UNEMP is a dummy varlable which equals one if the jobseeker is unemployed; $Q$ is a dummy varlable (Included in some specifications) for job leavers; and $X$ is a vector of varlables affecting the offer and wage offer functions. More speciflcally, the $X$ Include: age, education, marital status, race, local unemployment rates, urban residence, region (South vs, non-South), and famfly Income. 17

Equations for wage outcomes are closely related to these:

6)

$$
w=W\left(X, N U S E, T_{M}, w^{r}, \text { UNEMP, Q }\right)+e_{4}
$$

7)

$$
W^{\circ}=W^{\circ}\left(X, N U S E, T_{j} \text {, UNEMP, Q }\right)+e_{5}
$$

These specifications are based on the simple model of Equations 1) and 2) above with slight modifications. Thus Equations 3) and 6) are for the final employment and wage outcomes, which reflect all of the search choices and the underlying offer or wage offer functions respectively. They differ from the model above only in that search effort effects on wages as well as on offers are tested for here. Equations 4) and 7), for offers and wage offers, are Identical to Equations 3) and 6) except for the omission of the reservation wage term. Finally, Equation 5) for accepting offers is based simply on the comparison of reservation and offered wages. In all of these cases, the vartables for unemployment status are entered to measure restdual differences in search outcomes between the employed and unemployed once search cholces and other factors have been controlled for. 
A number of econometric issues must be briefly discussed here before turning to the actual results. For one thing, the search cholce and employment status varlables are treated as exogenous here. While search theorles stress that reservations wages and search effort are determined by expected outcomes, the dependent variables (and error terms) of the equations reflect actual outcomes. Expected outcomes are reflected in the $X$ variables above, which are used to capture the determinants of the offer and wage offer functions. The extent to which search cholces are truly exogenous with respect to observed outcomes will therefore depend on the completeness of the $X$ variables in explaining these functions. 13

As for the employment status varlables, the above specification abstracts from self-selection into this status. The low fraction of the unemployed accounted for by quits ( $11 \%$ in this sample) implies that the assumption of exogenous employment state for most searchers is reasonable here, and the inclusion of a dummy varlable for those who did quit allows for differences in the search behavior of that particular group.

Equations 3) - 5) and 6) - 7) are estimated independently here, thereby abstracting from possible correlations of errors across wage and employment equations.14 Equations 3) - 5), which have dichotomous dependent variables, are estimated by probit rather than oLS. The wage variables in all equations appear in log form.

Moving on to the results, Table 3 shows estimates of Equation 3) for the probability of gaining new employment. Specifications are presented with and without the job leaver varlable, as well as with and without search cholce variables. The results show that unemployed jobseekers are significantly more likely to gain new jobs than are employed seekers, even after controlling for personal characteristics and search choices. The sum of the coefficients for 
TABLE 3

Equations for the Probability of Gaining New Employment

Number of

Me thods Used

$\mathrm{L}_{\mathrm{n}}$ (Reservation Wage)

Time Spent Using:

Friends/Relatives

Direct Contact

State Agency

Newspapers

Other Methods

Unemployed

Job Leaver

$\log \mathrm{L}$ $\underline{1}$

\section{$\underline{2}$}

.142

$(.052)$

.242

$(.151)$

.004

$(.007)$

.003

$(.008)$

$-.020$

$(.020)$

$-.013$

(.013)

.061

$(.022)$

.342

$(.109)$

.416
$(.098)$

-

$-$

$-500.00$ $\underline{3}$

$\underline{4}$

.141

$(.052)$

.242

$(.151)$

.004

$(.007)$

.003

$(.008)$

$-.020$

$-(.020)$

$-.013$

(.013)

.061

$(.022)$

.364

(.111)

$-.177$

(.191)

$-.198$

$(.185)$

$-500.77 \quad-468.61$

NOTE: Equations estimated using Probit, Control variables for each equation include: age, education, marital status, race, region, urban residence, family income, local unemployment rate. Dummy variables are also included for missing values on time spent, which take on values of zero when missing. Sample size is 1045. Time spent variables are measured in hours. 
unemployment and for job leavers implies smaller but still positive effects for the latter.15 of the search cholce varlables, the number of methods used and time spent in other methods of search (1.e., those besides friends and relatives, direct contact, state agencies and newspapers) have positive and significant effects on the probability of gaining new employment. 16 But the addition of search cholce variables to the equation leaves the unemployment effect still significant here.

Table 4 presents estimates of Equations 4) and 5) which decompose the probability of gaining new employment into probabilities of receiving offers and accepting them. The results in this table show that the unemployed (excluding job leavers) recelve more offers than the employed jobseekers, though the difference is only marginally significant. Furthermore, most of this differential disappears when the search effort variables are added to the equation. In particular, the number of search methods used has an ever larger effect on receiving offers than on gaining new employment and appears to explain most of the differential attributed to unemployed jobseeking status. 17

In the equations for acceptance of offers, unemployed jobseekers accept substantially more offers than do employed jobseekers. As in Table 3, job leavers accept fewer offers than the other unemployed but still more than employed seekers. The ratio of reservation to recelved wages has the expected negative effect on job acceptance and is marginally significant, although $1 t$ explains only a small fraction of the coefficient on unemployed status.

Taken together, the results of Tables 3 and 4 confirm many of our previous predictions. In particular, the unemployed recelve and accept more offers than do employed seekers. Virtually all of their higher rate of recelving offers and at least part of their higher rate of accepting them are due to their choices of more extensive search and lower reservation wages 
Equations for the Probability of Recelving and Accepting Job offers

\section{Receiving offers}

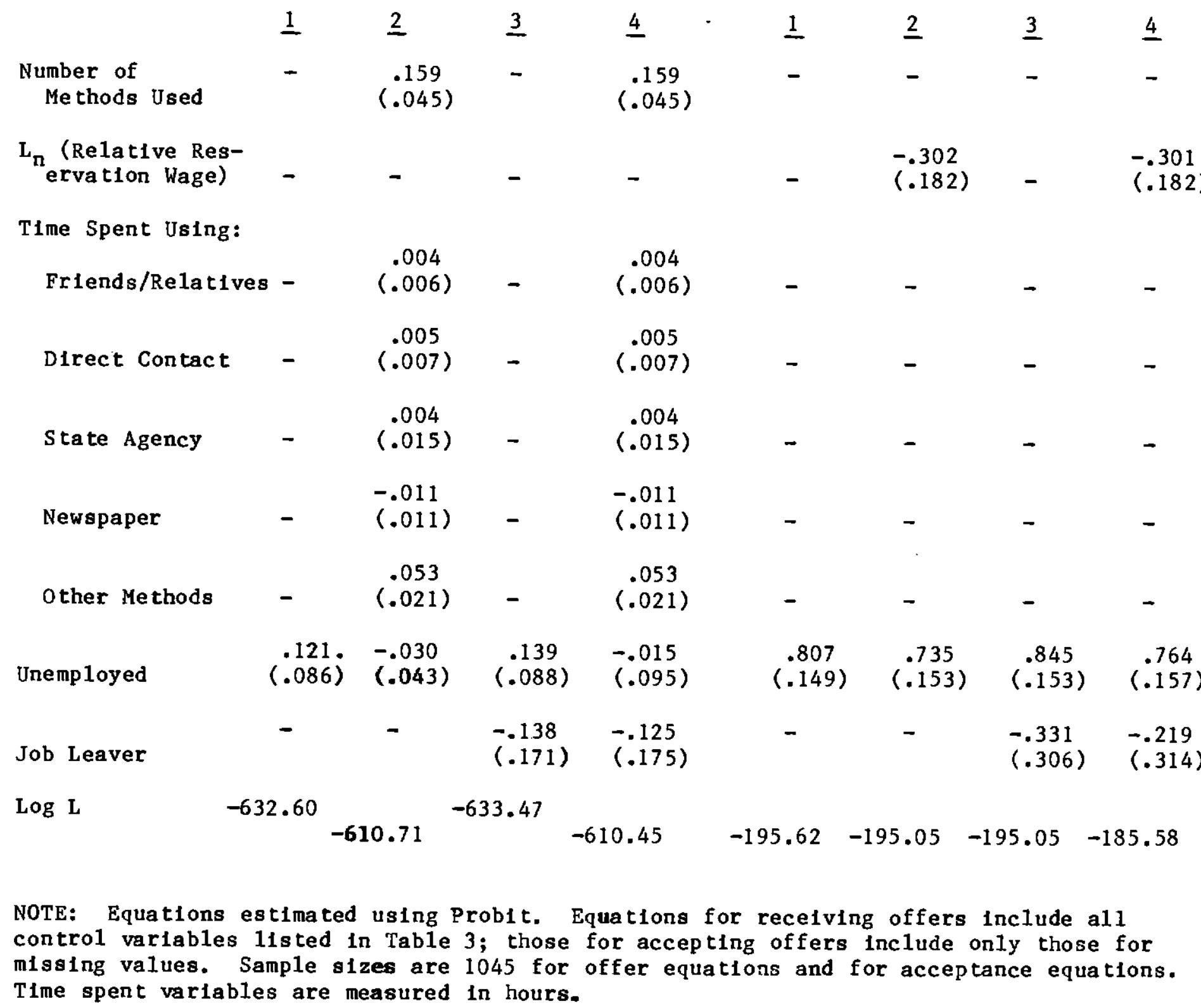

\section{Accepting offers}

4 
respectively. Furthermore, it is quite likely that the true effect of reservation wages on the differential acceptance rate is understated here, due to the problems of measurement error in reservation wages and unobservable skills.18 In fact, the acceptance or rejection of offers in virtually all job search models is caused exclusively by comparisons of wage offers and reservation wages, which would imply that all of the differential between the unemployed and employed reflects relative differences in their true (as opposed to observed) reservation and offered wages. Either way, the role of search choices in explaining differences between employed and unemployed jobseeking outcomes appears to be fairly important; and observed differences in both choices and outcomes conform quite well to the predictions of the theory outlined above.

In Table 5 we turn to estimates of Equations 6) and 7) for offered and accepted wages. The results indicate that both offered and accepted wages are just a bit higher for employed seekers when controlling for personal characteristics, though the differences are not significant in either case. The search effort measures seem to have few (or incorrect) effects on wages. However, reported reservation wages have large and significant effects on recelved wages. In fact, their inclusion reverses the direction of the effect of unemployed job search from a negative to a positive one on recelved wages. This positive effect is largest for unemployed job leavers. of course, the direction of the bias on coefficients for reservation wages in these equations is less clear than in employment equations, since unobserved skill now has a positive rather than negative effect on estimated results. 19 But even if the measured reservation wage captures heterogenity as well as true search choices, it appears to be responsible for the higher (or comparable) wages employed jobseekers receive in summary measures and in 
TABLE 5

Equations for Offered and Accepted Wages

Offered Wages

$1 \quad \underline{2} \quad \underline{3}$

Number of

Methods Used

$\mathrm{L}_{\mathrm{n}}$ (Reservation

Wage)

Time Spent Using:

\begin{tabular}{|c|c|c|c|c|c|c|c|c|c|}
\hline & Frlends/Relatives & - & $\begin{array}{l}.001 \\
(.004)\end{array}$ & - & $\begin{array}{l}.001 \\
(.004)\end{array}$ & - & $\begin{array}{l}-.002 \\
(.004)\end{array}$ & - & $\begin{array}{r}-.002 \\
(.004)\end{array}$ \\
\hline & Direct Contact & - & $\begin{array}{l}-.002 \\
(.005)\end{array}$ & - & $\begin{array}{l}-.002 \\
(.005)\end{array}$ & - & $\begin{array}{l}-.005 \\
(.005)\end{array}$ & - & $\begin{array}{l}-.005 \\
(.005)\end{array}$ \\
\hline & Sta te Agency & - & $\begin{array}{l}-.005 \\
(.007)\end{array}$ & - & $\begin{array}{l}-.004 \\
(.007)\end{array}$ & - & $\begin{array}{l}.005 \\
(.012)\end{array}$ & - & $\begin{array}{l}.006 \\
(.012)\end{array}$ \\
\hline & Newspapers & - & $\begin{array}{c}-.001 \\
(.009)\end{array}$ & - & $\begin{array}{l}-.001 \\
(.009)\end{array}$ & - & $\begin{array}{l}.010 \\
(.009)\end{array}$ & - & $\begin{array}{l}.010 \\
(.009)\end{array}$ \\
\hline & Other Methods & - & $\begin{array}{c}-.001 \\
(.005)\end{array}$ & - & $\begin{array}{l}-.001 \\
(.005)\end{array}$ & - & $(.003)$ & - & $\begin{array}{l}.003 \\
(.006)\end{array}$ \\
\hline Unemp & iployed & $\begin{array}{l}-.041 \\
(.044)\end{array}$ & $\begin{array}{l}-.007 \\
(.048)\end{array}$ & $\begin{array}{c}-.044 \\
(.045)\end{array}$ & $\begin{array}{l}-.011 \\
(.049)\end{array}$ & $\begin{array}{l}-.036 \\
(.056)\end{array}$ & $\begin{array}{l}.069 \\
(.054)\end{array}$ & $\begin{array}{l}-.042 \\
(.057)\end{array}$ & $\begin{array}{r}.060 \\
(.055)\end{array}$ \\
\hline Job I & Leaver & - & - & $\begin{array}{l}.033 \\
(.094)\end{array}$ & $\begin{array}{l}.033 \\
(.095)\end{array}$ & - & $\rightarrow$ & $\begin{array}{l}.079 \\
(.112)\end{array}$ & $\begin{array}{l}.095 \\
(.095)\end{array}$ \\
\hline$\overline{\mathrm{R}}^{2}$ & & .046 & .055 & .043 & .052 & .096 & .364 & .093 & .364 \\
\hline
\end{tabular}

Accepted Wages

$\underline{1} \quad \underline{2} \quad \underline{3} \quad \underline{4}$

\begin{tabular}{l}
$-016 \quad-\quad .016$ \\
\hline
\end{tabular}

$(.026) \quad(.026)$

$-\quad \begin{aligned} & .579- \\ & (.071)\end{aligned} \quad(.581)$
Time Spent Using:

NOTE: Control varlables in each equation are those l1sted in Table 3 . Dependent variables appear in natural logarithms. Sample sizes are 254 for of fered wage equations and 173 for accepted wage equations. Time spent variables are measured in hours. Relative reservation wages are defined as the ratio of reservation to offered wages. An extra dummy vartable has been added for cases where offered wages are missing. 
equations which do not control far search cholce. Thus employed search per se does not appear to cause higher wage offers, as was suggested in some of the earlier studies. Once again, differences in search choices between the employed and unemployed jobseekers help to explain search outcomes which we observe for the two groups.

\section{Conclusion}

In this paper I argue that the higher costs of search for unemployed as opposed to employed jobseekers should lead the former to undertake high levels of search effort and to have lower reservation wages relative to offered wages. These prefictions are borne out by emplrical evidence on young male jobseekers which shows that the number of search methods used and the time spent per method are higher for unemployed searchers, while their relative reservation wages are lower. Furthermore, these differences in search choices help to explain some of the differences in outcomes which we also observe between the two groups. In particular, the higher number of search methods used explains most of the higher probability of recelving offers which we find for the unemployed. Also, the lower relative reservation wages of the unemployed explain at least part of the substantially higher job acceptance rate and mildiy lower recelved wage rates which we find for that group. All of this is consistent with a picture of unemployed searchers being more eager to find new work, given the higher costs of search which they bear.

A few important caveats must be kept in mind when considering these results. For one thing, they do not appear to hold for those who select unemployed jobseeking status by leaving their previous jobs. However, such 
14

voluntary terminations account for only a small fraction of unemployed jobseekers. Measurement problems and other econometric issues also create biases here which leave the exact magnitudes of search choice effects on outcome very uncertain. Finally, the focus on young jobseekers enables us to downplay the Importance of Unemployment Insurance and temporary layoffs, though these factors are probably more critical for older cohorts.

Despite these difficulties, the evidence strongly suggests that the search choices of employed and unemployed jobseekers differ and that these choices have important effects on the differences in outcomes which we observe between the two groups. 


\section{FOOTNOTES}

$1_{\text {For }}$ instance, the claim has been made that reservation wages should be Irrelevant, and no one should ever turn down a job offer, if they can continue to search as (or more) effectively while being employed. See Clark and Summers (1979) for such a claim, and Burdett (1978) for a model which incorporates such a notion.

${ }^{2}$ Yoon (1981) distinguishes between fixed and unit search costs, where the former reflect the costs of being unemployed and the latter reflect the costs per unit of search effort. He shows that fixed costs should be directly related and variable costs inversely related to search effort. In this context, the receipt of earnings would lower fixed costs and therefore search effort for the employed. Barron and Mellow (1979) also argue that search effort should be inversely related to the cost of being unemployed, where the latter term is reduced by nonwage income.

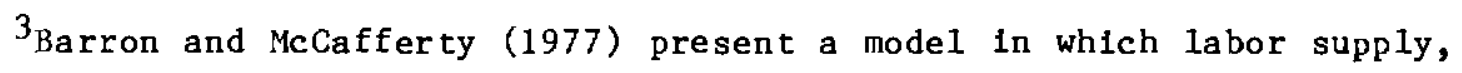
leisure, and search effort are simultaneously determined, and in which an individual can choose unemployed search (1.e., zero labor supply) by quitting. In that model, labor supply and search effort respond in opposite fashions to changes in exogenous factors such as real wages and vacancy rates. Kahn and Low (1984) explicitly Iink unemployed status while searching to a low level of search effort by claiming that the decision to quit a job is based on a desire to raise search effort above some critical level, above which employment is no longer possible. 
${ }^{4}$ For a varlety of we11-known reasons, we expect reservation wages to decline as the spell continues for the unemployed; whether this is true for the employed jobseeker is less clear. Thus the 1mplications of these dynamic factors for the comparison of employed and unemployed search cholces are uncertain.

${ }^{5}$ According to data in the Handbook of Labor Statistics (1983), the fractions of the unemployed accounted for by job leavers, job losers, and labor force entrants in 1982 are .069, .233, and .698 respectively. For a non-recession year such as 1978, the fraction accounted for by job leavers rises only to .104 .

${ }^{6}$ The search methods listed include friends and relatives, direct contact without referral, state employment agencles, newspapers, and several more formal but less frequently used channels for seeking employment. Throughout the analysis in this paper, five search methods will be considered: the four listed above and a fifth category which includes all of the remaining ones.

${ }^{7}$ The amount of time spent on each method has been adjusted to obtain a correct measure of Intensity for those who accepted jobs and therefore stopped searching during the month. The adjustment factor is $(30-D) / 30$, where D 1s duration of employment on the current job. Th1s factor thus reflects the percentage of days in the previous month during which search was still taking place. 
${ }^{8}$ The distinction used here between extensive and intensive search is closely related to the definition developed by Rees (1966). It was not possible to combine these measures into a single measure of total time spent searching because of missing values which appear in different search methods for different people, thereby making aggregation very difficult.

${ }^{9}$ The restriction of the analysis to males is done because of the huge differences in search behavior and labor market outcomes between males and females. A similar rationale applies to the elimination of enlisted people and students from the sample.

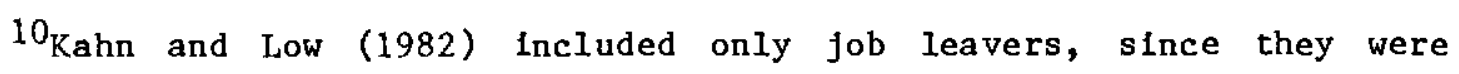
focusing on the cholce of employment status while searching as well as on outcomes. Gottschalk and Maloney (1985) included job losers and leavers but not entrants, since their outcome variable involves a comparison between old and new fobs. Since outcomes in both papers deal with characteristics of new jobs, only successful job changers are Included (though Gottschalk and Maloney account for selection into this category). But since successful completion of search is an explicit outcome in my work, and since previous jobs are not needed for any of these outcomes, I have included all of the unemployed here. As noted, only the distinction between fob leavers and others is crucial here, and this distinction is made in econometric work discussed below.

${ }^{11}$ Computed standard errors on weighted means are generally not correct, since population rather than sample sizes are used during the computation. But standard errors for unwelghted means give a falrly good 
Indication of the relevant ones. Unweighted standard errors for the employed and unemployed on number of search methods used are .060 and .051 respectively, while for reservation wages of those with offers they are .276 and .159 respectively. Since the standard error of the difference in parameters between Independent samples is the square root of the sum of squared Individual standard errors, the differences appear to be significant In the above cases. Differences between employed and unemployed search times are simflarly significant in most cases.

12 Additional dummy varlables have been included in these equations to account for missing values in the $\mathrm{TIME}_{\mathrm{j}}$ varlables and in $\mathrm{w}^{\circ}$. In cases of missing values, these latter varlables take on the value of zero while the dummy varlables take on the value of one. The TIME $\mathrm{f}$ varlables also have values of zero when any search method has not been used by a jobseeker.

${ }^{13}$ Treating search choices as exogenous in outcome equations enables us to avold specifying equations for the determinants of these choices. Since the effects of Unemployment Insurance presumably work through these search cholces, we omft UI from the outcome equations. While temporary layoffs with high chance of recall should affect search outcomes directly as well as through the cholce varlables, the small number of young workers who are on such layoffs and the Incompleteness of this varlable in the NLS (caused by missing values and changes in employment status of individuals over the month) have led us to omit this varlable from these equations as well.

${ }^{14}$ The estimation of independent equations for wage and employment outcomes of search follows Ehrenberg and Oaxaca (1976). More structural 
models of the search process have recently been developed by Kiefer and Neumann (1979), among others.

${ }^{15}$ The coefficient on the quit variable must be added to that of the unemployment variable, since both have a value of one for job leavers. The variable in the NLS which was used to create the dummy variable for quits was the one which establishes reason for unemployment--job leaving, job loss, etc. Since this question was also asked only of the currently unemployed, there were no responses for many of the unemployed who had accepted jobs and begun working. In particular, $14 \%$ of those counted as unemployed in this sample failed to answer this question, though these individuals account for $33 \%$ of those recelving offers and $39 \%$ of those accepting offers. This higher omission rate among successful searchers thus suggests that estimated effects of the quit variable on employment outcomes may be blased downwards.

${ }^{16}$ The finding that the number of search methods used has a significant positive effect on employment probabilities stands in sharp contrast to the recent results of Keeley and Robbins (1985), who found negative effects. Possible reasons for the discrepancy include differences in samples and in specifications. In particular, they use intermediate outcomes (e.g., number of firms contacted) as independent variables in addition to cholce varlables, and the former may be picking up the latters' effects.

${ }^{17}$ Equations in which NUSE is the only search cholce variable produce virtually the same decline in the effects of unemployed search as in the equations presented. 


\begin{abstract}
${ }^{18}$ Unobserved skills produce a downward blas due to their presumed positive correlation with reservation wages and their negative correlation with probabilities of recelving and accepting offers. Measurement error, which also produces a downward blas on estimated effects, results from the subjective and hypothetical nature of the self-reported reservation wage. A further measurement problem involves the current nature of the reservation wage question in the NLS Survey. Given that many searchers have already accepted new offers and begun working, the reported reservation wages may not reflect the true ones during their period of search.
\end{abstract}

${ }^{19}$ In this case unobserved skills are positively correlated with both reservation wages and offered or accepted wages, thus producing a positive bias. 


\section{REFERENCES}

Barron, John and Stephen McCafferty. "Job Search, Labor Supply and the Quit Decision." American Economic Review, September 1977.

and Wesley Mellow. "Search Effort in the Labor Market." Journal of Human Resources, Summer 1979.

Black, Matthew. "Pecuniary Implications of On-The-Job Search and Quit Activity." Review of Economics and Statistics, May 1980.

- "An Empirical Test of the Theory of On-The-Job Search." Journal of Human Resources, Winter 1981.

Burdett, Kenneth. "A Theory of Employee Job Search and Quit Rates." American Economic Review, March 1978.

Clark, Kim and Lawrence Summers. "The Dynamics of Unemployment: A Reconsideration." Brookings Papers on Economic Activity, 1979: 1.

Ehrenberg, Ronald and Ronald Oaxaca. "Unemployment Insurance, The Duration of Unemployment and Subsequent Wage Growth" American Economic Review, December 1976.

Gottschalk, Peter and Tim Maloney. "Involuntary Terminations, Unemployment and Job Matching," Journal of Labor Economics, Apri1 1985. 
Kahn, Lawrence and Stuart Low. "The Relative Effects of Employed and
Unemployed Job Search." Review of Economics and Statistics, May 1982.

and - "An Empirical Model of Employed Search, Unemployed Search, and Nonsearch." Journal of Human Resources, Winter 1984.

Keeley, Michael and Philfp Robbins. "Government Programs, Job Search Requirements, and the Duration of Unemployment." Journal of Labor Economica, July 1985.

Kiefer, Nicholas and George Neumann. "An Empirical Job-Search Model with a Test of the Constant Reservation Wage Hypothesfs," Journal of Political Economy. February 1979.

Lippman, Stephen and John McCal1. "The Economics of Job Search: A Survey." Economic Inquiry, June 1976.

Mattila, J. Peter. "Quft Behavior in the Labor Market." American Statistical Assoclation Proceedings, 1969.

Rees, Albert. Tnformation Networks in Iabor Markets." American Economic Review, May 1966.

Yoon, Bong Joon. "A Molel of Unemployment Duration with Variable Search Intensfty." Review of Economics and statistcs, November 1981. 